\title{
ANALYSIS OF STRUCTURES WITH SOME UNCOMMON IRREGULARITIES- TYPICAL FINDINGS
}

\author{
Anuja Pawar ${ }^{1}$ and Anant Pande ${ }^{2}$ \\ ${ }^{1}$ PG Student, Department of Civil Engineering \\ ${ }^{2}$ Professor, Department of Civil Engineering \\ ${ }^{1,2}$ Yeshwantrao chavan college of Engineering, Nagpur-441110 \\ Email: ${ }^{1}$ anujapawar560@gmail.com $\}^{2}$ \{anantpande.ycce@gmail.com\}
}

\begin{abstract}
Architects are focusing on planning high-rise structures with various irregularities, there is a great deviation from the expected simple and symmetric configuration to irregular configurations. The IS 1893:2016 has detailed many vertical as well as horizontal irregularities in structures. Many technical papers are available on stiffness irregularity, mass irregularity, diaphragm irregularity, torsional irregularity, however no much research work is available in literature on some uncommon irregularities such as vertical geometric irregularity, floating or stub columns, non-parallel lateral force system. Thus there is a great need to investigate development of forces, displacements and storey drift in the structures with these irregularities and understand the limitations and scope for seismic safety of these structures. The analyses of structures with vertical geometric irregularities have clearly demonstrated that the column location and its position from the plane of major stiffness variation play important role in development of forces and displacements. The outcome of this research paper shall prove to be beneficial while designing structures with vertical geometric irregularity.
\end{abstract}

Key words:- Uncommon Irregularity, Vertical Geometric Irregularity, Stiffness variation, Storey Drift.

\section{Introduction}

Structural engineers are before different new developments in planning safe structures because of an expansion in the extreme activities surrendered on structures which has the imminent to cause incredible annihilation, harm and hazard to individuals. A vast part of India is susceptible to have an adverse effect on structures due to the seismic hazards. Hence it is important to take a note of seismic load for the design of high rise structures [2]. The conduct of a building during seismic tremors depends on its general shape, size and geometry, not withstanding how the seismic tremor forces are conveyed to the ground [1]. The earthquake forces created at various floor levels in a building should be transferred down along the height to the ground by the shortest path; any deviation or discontinuity in this load transfer path results in the poor execution of the building [3]. Proper design considerations along with appropriate safety measures can result in the seismic safety of structure with vertical geometric irregularity [4]. We have to examine the critical column locations and the increment in the forces and displacement due to the irregularities in structures. By finding these critical locations the plan of the building can be advanced.

In this paper, a $\mathrm{G}+17$ regular ideal structure is analyzed and designed by using STAAD-PRO Software and also three different models having vertical geometric irregularity are analyzed and designed by using same Software. In the models having vertical geometric irregularity, the irregularities are introduced following the Guidelines as specified in IS 1893:2016. Three different limits are adopted for three different models.

\section{Study of Codal Provisions}

For the design of structures with vertical geometric irregularity, Indian Standard Code IS 1893:2016 has specified some guidelines. The guideline is as follows:-

\section{Vertical irregularity}

a) Vertical Geometric Irregularity:

"Vertical geometric irregularity shall be considered to exist, when the horizontal dimension of the lateral force resisting system in any storey is more than 125 percent of the storey below."

\section{Methodology}

Initially a $\mathrm{G}+17$ regular ideal structure is analyzed and designed by using Staad-Pro Software. Then three models having vertical geometric irregularity are analyzed and designed. For considering the vertical geometric irregularity IS 1893:2016 has specified a limit of 125 percent. While creating the models with vertical geometric irregularity we have adopted three limits, one limit equal to 125 percent, other limit lesser than 125 percent i.e, a limit of 100 percent and the third limit of 150 percent which is greater than 125 percent. For the analysis of structures the grade of concrete used is M30 and the grade of steel used is Fe-415. Seismic analysis of ideal structure and the set of structure with vertical geometric 
irregularity were performed by using Equivalent Static Analysis approach. The plan and elevation of Regular ideal structure is shown in figure 1 and 2 . The structures with vertical geometric irregularity are as shown in figure 3.

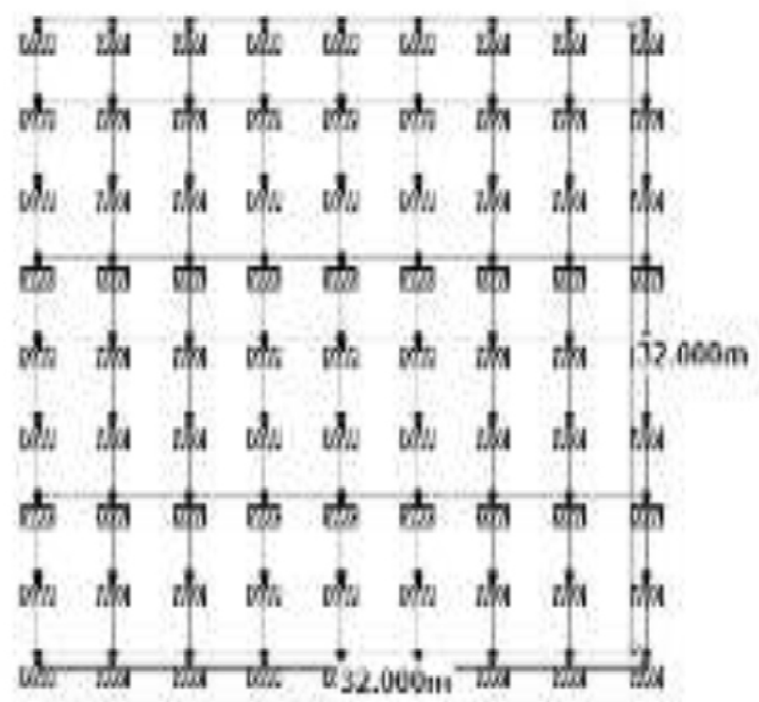

Fig. 1 : Plan of ideal structure.

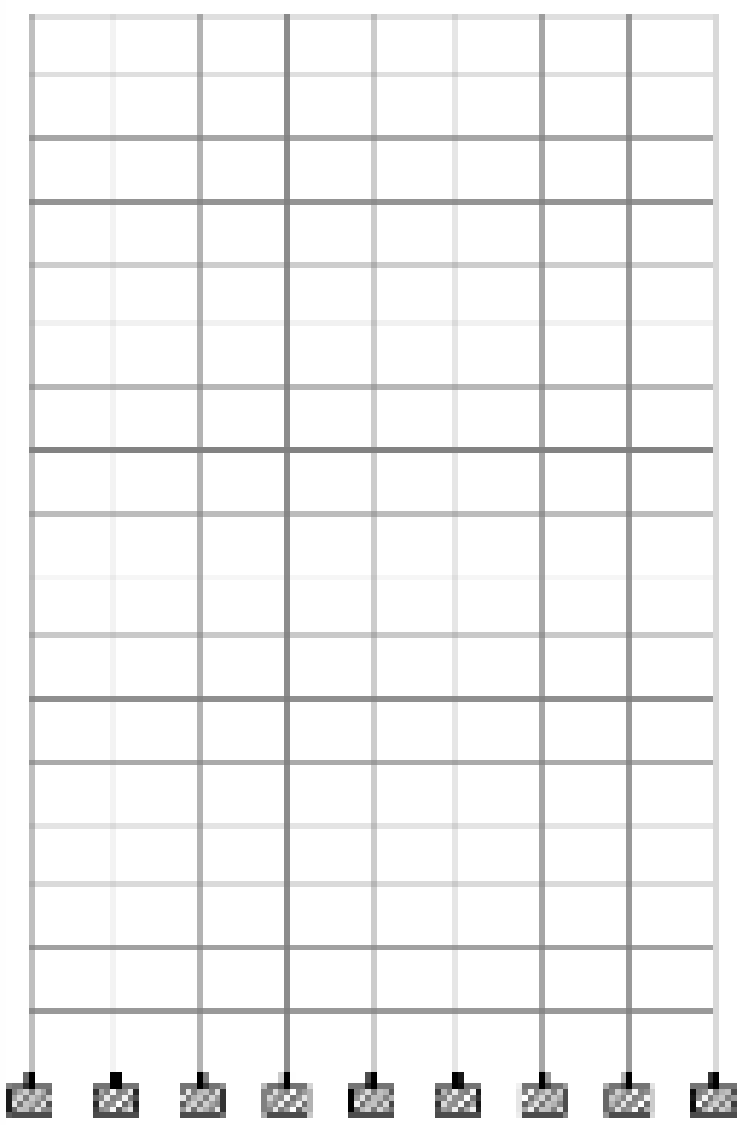

Fig. 2 (a) : Elevation view of ideal structure.

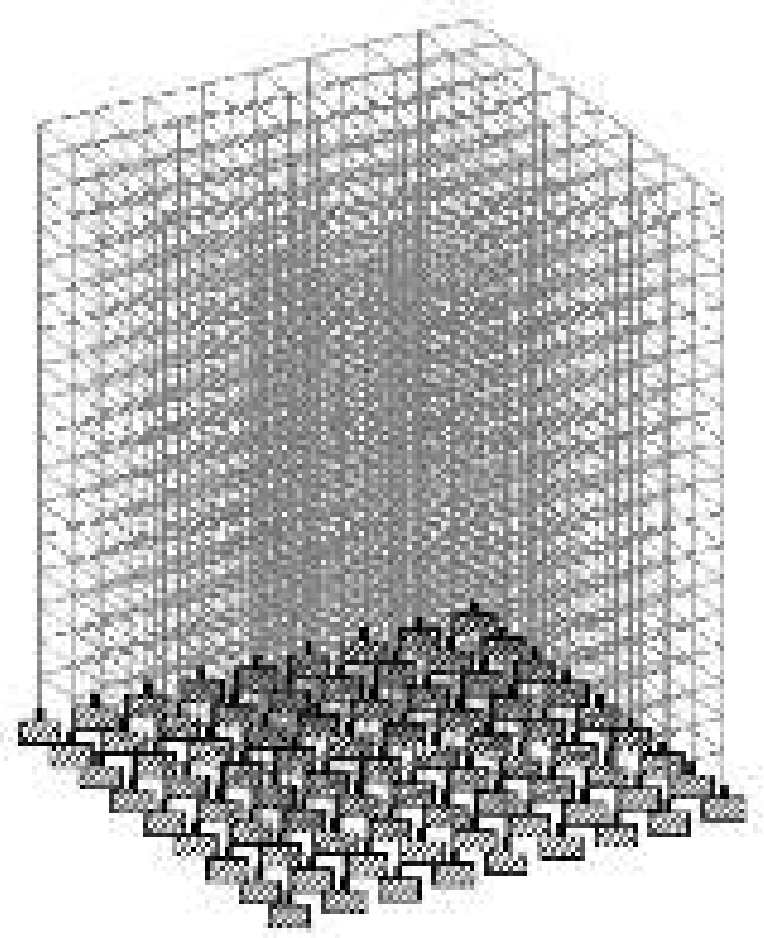

Fig. 2 (b) : Isometric view of ideal structure.

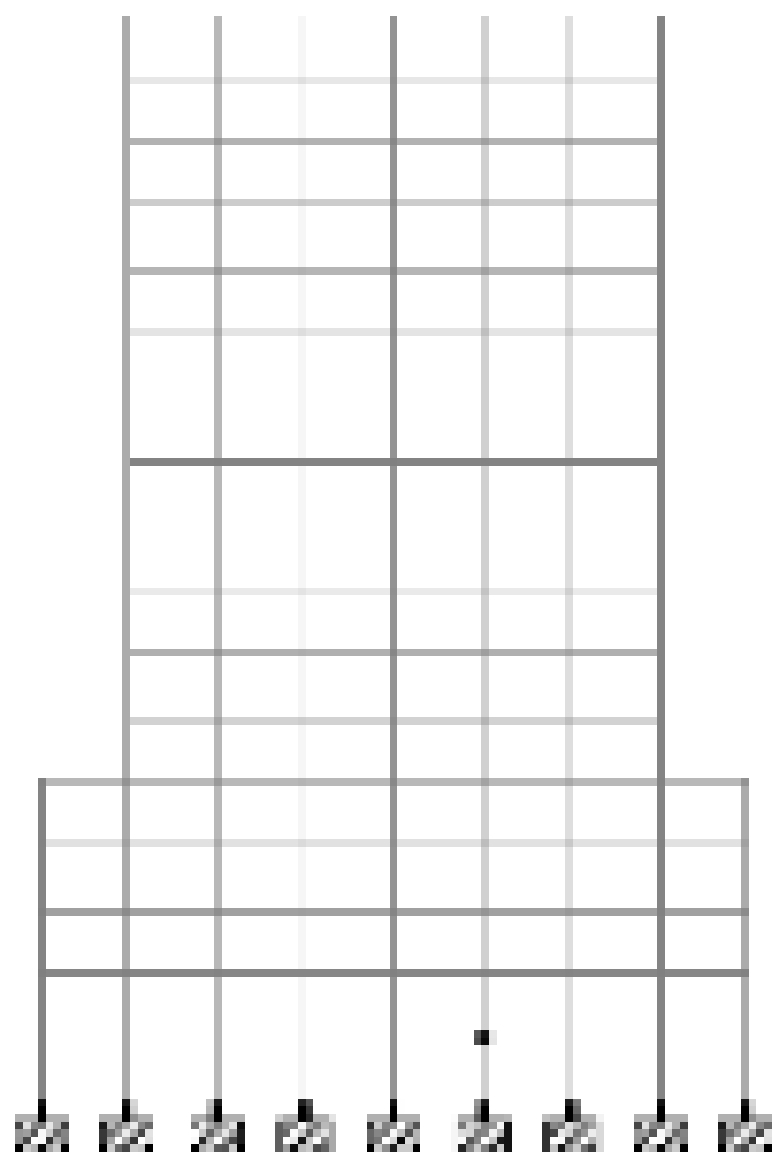

Fig. 3 (a) : Models with $100 \%$ limit 


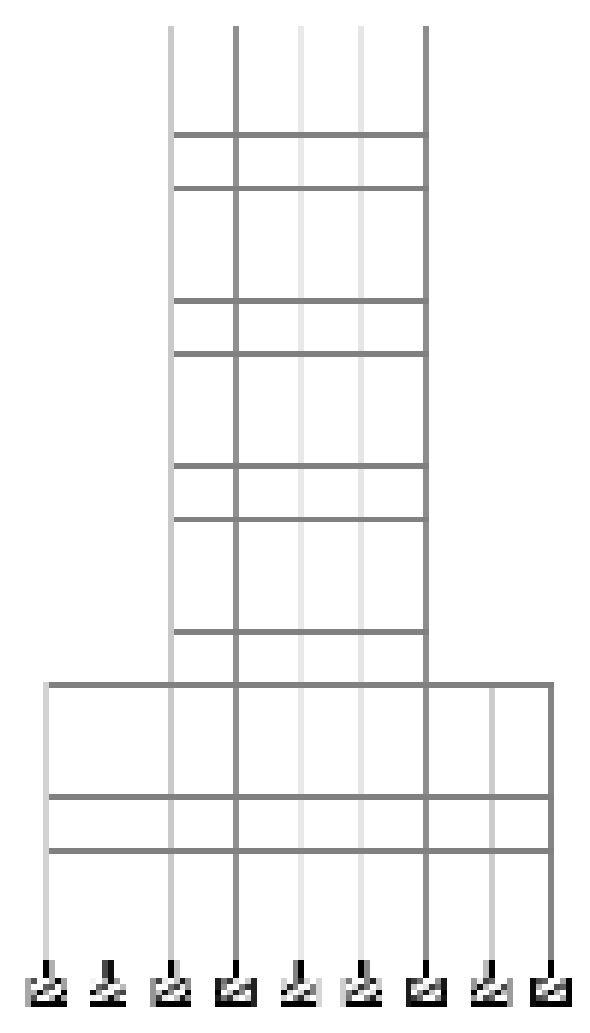

Fig. 3 (b) : Models with 125\% limit

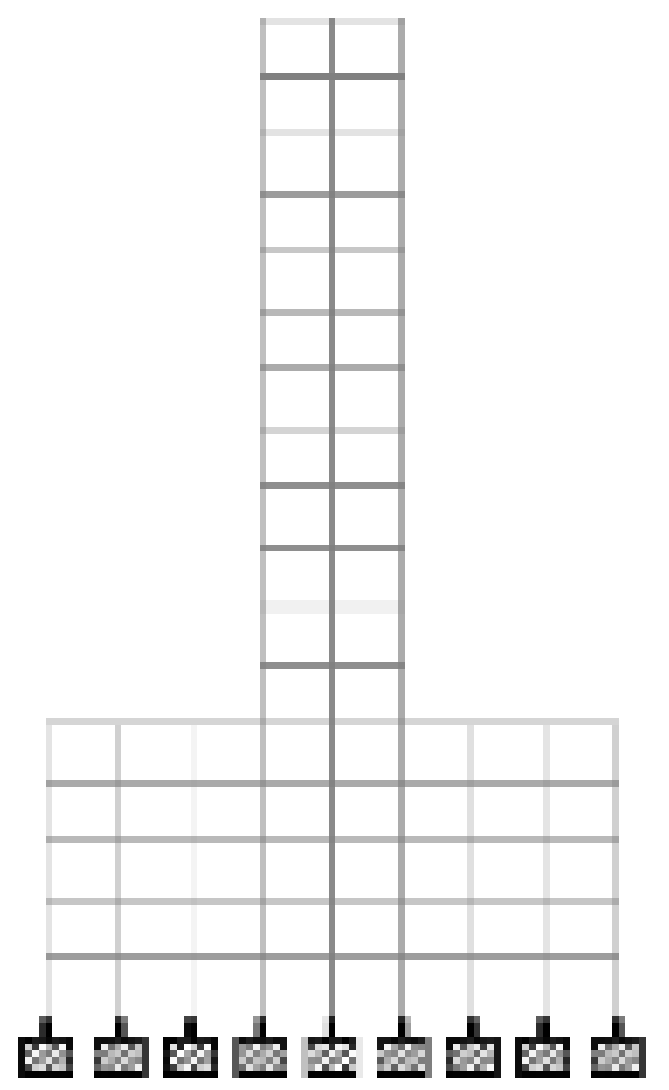

Fig. 3 (c) : Models with 150\% limit

Fig. 3 : Models with Vertical Geometric Irregularity
A) Seismic Analysis Data

Table 1

(As per IS 1893:2016)

\begin{tabular}{|c|l|c|}
\hline Sr. No. & \multicolumn{1}{|c|}{ Parameters } & Factors \\
\hline 1 & Zone III & 0.16 \\
\hline 2 & Response Reduction Factor $(\mathrm{R})$ & 5 \\
\hline 3 & Importance Factor $(\mathrm{I})$ & 1 \\
\hline 4 & Type of structure & 1 \\
\hline 5 & Damping Ratio & 0.05 \\
\hline 6 & Period in X direction $(\mathrm{Px})$ & 0.81 \\
\hline 7 & Period in Y direction $(\mathrm{Py})$ & 0.81 \\
\hline
\end{tabular}

\section{B) Structural Details}

The ideal structure and the structures with irregularity are having same specifications.

Table 2

(Building Specifications)

\begin{tabular}{|c|l|c|}
\hline Sr. No. & \multicolumn{1}{|c|}{ Parameters } & Details \\
\hline 1 & Length of Building & $32 \mathrm{~m}$ \\
\hline 2 & Width of Building & $32 \mathrm{~m}$ \\
\hline 3 & Height of Building & $51 \mathrm{~m}$ \\
\hline 4 & Slab Thickness & $150 \mathrm{~mm}$ \\
\hline 5 & Concrete Grade & M30 \\
\hline 6 & Steel Grade & Fe415 \\
\hline
\end{tabular}

\section{C) Loading Data}

Table 3

(Loading Data)

\begin{tabular}{|c|c|c|}
\hline Sr. No. & Loading Type & Loading \\
\hline 1 & Member Load & $13.8 \mathrm{kN} / \mathrm{m}^{2}$ \\
\hline 2 & Dead Load & $3.75 \mathrm{kN} / \mathrm{m}^{2}$ \\
\hline 3 & Live Load & $3 \mathrm{kN} / \mathrm{m}^{2}$ \\
\hline
\end{tabular}

\section{Result And Discussion}

\section{A. Column Forces:-}

Nine column positions are considered as critical column positions and by making use of Microsoft Excel graphs are plotted. The Graphs so plotted represents a comparison between the column forces of regular structure with the forces of irregular structure. Only two load cases appear to give maximum forces, i.e,
a) $\quad 1.5$ (D.L.+EQX.)
b) $\quad 1.5$ (D.L.-EQX.)

Important graphs are presented in fig. 4 to 7 : 


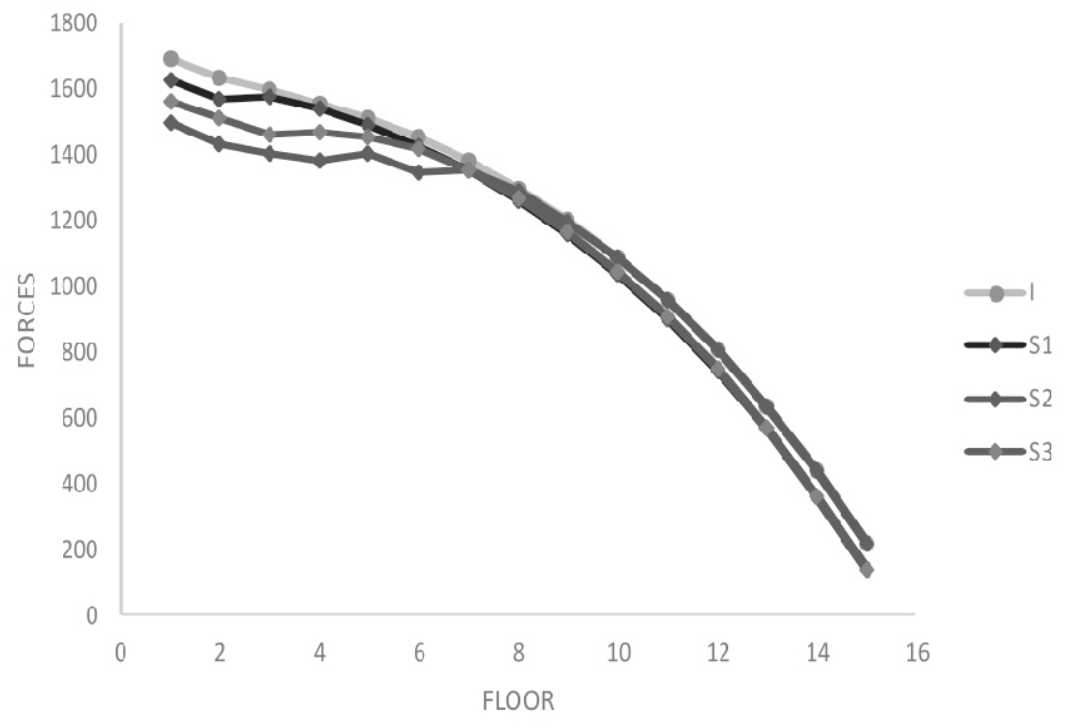

Fig. 4 : Floorwise Variation in Shear Force
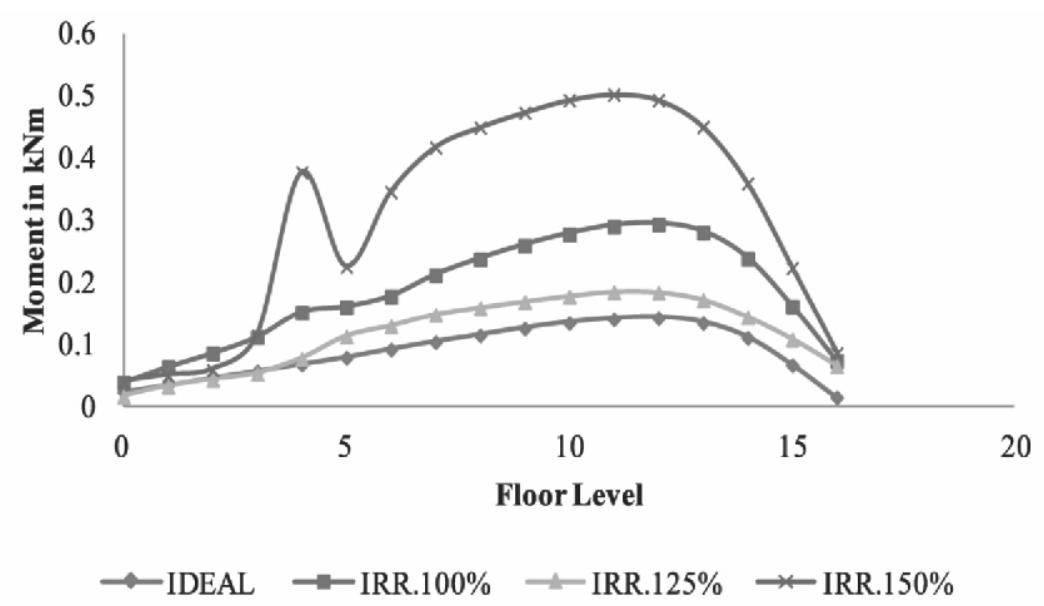

Fig 5. : Floorwise variation in torsion

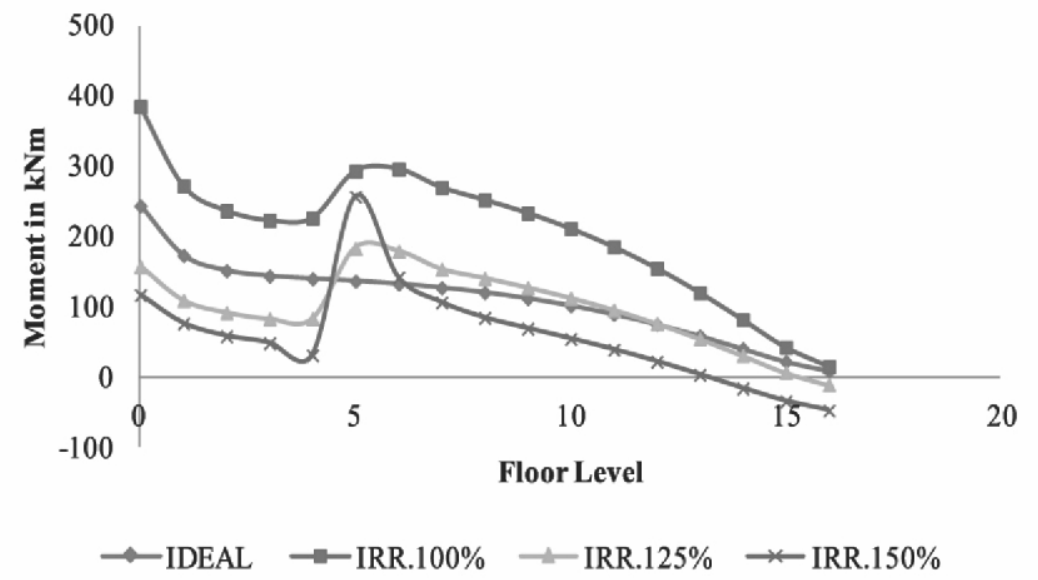

Fig. 6 : Floorwise variation in lateral moments 


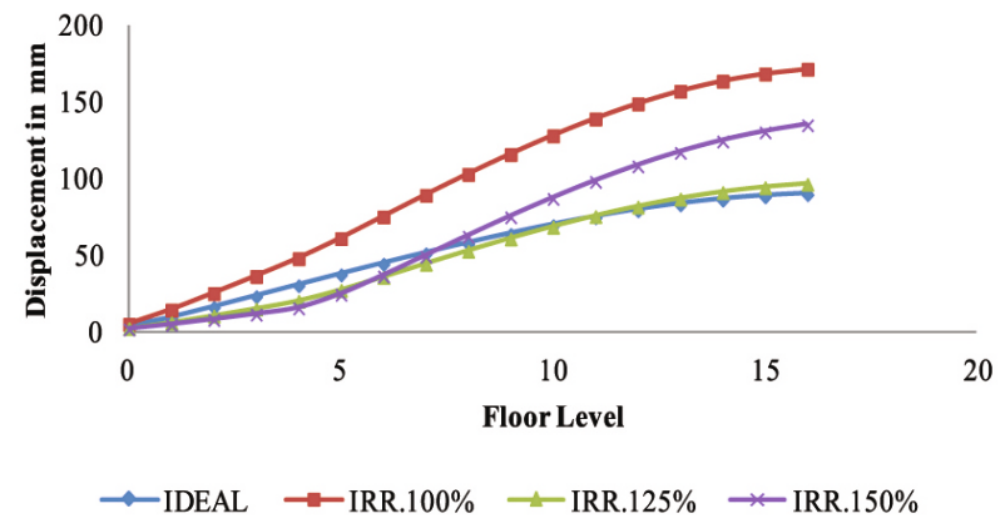

Fig. 7 : Floorwise variation in displacement in the direction of earthquake force

Column positions play important role in development of forces and displacements. Column which is close to the vertical geometric irregularity may experience forces. Typical observations from figures 4 to 7 are

1. Lateral shear force may be much more in case of $100 \%$ irregularity than the other cases. With the increase in irregularity this may irratically deacrease. (Fig. 4)

2. Torsion in the selected column shows irratic increase, torsion at middle floors is much higher for the $150 \%$ geometric irregularity while the ideal structure shows lowest torsion. (Fig. 5)

3. Similar observations are seen in case of lateral moments. (Fig. 6)

4. Displacement may be much more in case of $100 \%$ irregularity than the other cases. With the increase in irregularity this may irratically increase or deacrease. (Fig. 7)

\section{Conclusion}

Vertical geometric irregularities may result in erratic increase or decrease in torsions, shears and displacements. Position of column from the plane of major stiffness variation plays important role in these. $50 \%$ of geometric irregularity does not play a direct role in development of forces and displacements in all columns. The results may significantly vary with the configuration and column positions.

\section{References}

[1] Shaikh Abdul Aijaj Abdul Rahman, Ansari Ubaidurrahman Salik, "Seismic Analysis of Vertically Irregular Buildings", Current Science, Vol. 111, No. 10, November 2016.
[2] Prof. S.S.Patil, Miss S.A.Ghadge, Prof. C.G.Konapure, Prof. Mrs. C.A.Ghadge, "Seismic Analysis of High-Rise Building by Response Spectrum Method", International Journal of Computational Engineering Research, Vol. 3, Issue. 3, Elsevier.

[3] E. Pavan Kumar, A. Naresh, M. Nagajyothi, M. Rajashekhar, "Earthquake Analysis of MultiStoreyed Residential Building-A case Study", International Journal of Engineering Research and Applications, ISSN: 2248-9622, Issue 11, November 2014, pp. 59-64.

[4] Chatpan Chintanapakdee, Anil K. Chopra, "Seismic Response of Vertically Irregular Frames: Response History and Modal Pushover Analysis", Journal of Structural Engineering (C) ASCE/ AUGUST 2004/1177.

[5] Egor P. Popov, Carl E. Grigorian and Tzong- Shuoh Yang, "Developments in Seismic Structural Ananlysis and Design", Engineering Structures, Vol. 17, No. 3,pp. 187-197, 1995 (C) Elsevier.

[6] George Georgoussis, Achilleas Tsompanos, Triantafyllos Makarios, "Approximate Seismic Analysis of Multi-Storey Buildings with mass and stiffness irregularities", The Fifth International Conference of Euro Asia Civil Engineering Forum, Procedia Engineering 125 (2015) 959-966, Elsevier.

[7] Pradip Sarkar, A. Meher Prasad, Devdas Menon, "Vertical Geometric Irregularity in Stepped Building Frames", Engineering Structures 32 (2010) 2175-2182, Elsevier. 